\title{
Fragmentation of Isomeric Intrastrand Crosslink Lesions of DNA in an Ion-Trap Mass Spectrometer
}

\author{
Huachuan Cao and Yinsheng Wang \\ Department of Chemistry, University of California at Riverside, Riverside, California, USA
}

The collision-induced dissociation pathways of isomeric cytosine-guanine and cytosineadenine intrastrand crosslink-containing dinucleoside monophosphates were investigated with the stable isotope-labeled compounds to gain insights into the effects of chemical structure on the fragmentation pathways of these DNA modifications. A Dimroth-like rearrangement, which was reported for protonated 2'-deoxycytidine and involved the switching of the exocyclic N4 with the ring N3 nitrogen atom, was also observed for the cytosine component in the protonated ions of $\mathrm{C}[5-8] \mathrm{G}, \mathrm{C}[5-2] \mathrm{A}$, and $\mathrm{C}[5-8] \mathrm{A}$, but not $\mathrm{C}\left[5-\mathrm{N}^{2}\right] \mathrm{G}$ or $\mathrm{C}\left[5-\mathrm{N}^{6}\right] \mathrm{A}$. In these two sets of crosslinks, the $\mathrm{C} 5$ of cytosine is covalently bonded with its neighboring purine base via a carbon atom on the aromatic ring and an exocyclic nitrogen atom, respectively. On the contrary, the rearrangement could occur for the deprotonated ions of $\mathrm{C}\left[5-N^{2}\right] \mathrm{G}, \mathrm{C}\left[5-\mathrm{N}^{6}\right] \mathrm{A}$, and unmodified cytosine, but not $\mathrm{C}[5-8] \mathrm{G}$, $\mathrm{C}[5-2] \mathrm{A}$, or $\mathrm{C}[5-8] \mathrm{A}$. In addition, ammonia could be lost more readily from $\mathrm{C}\left[5-\mathrm{N}^{2}\right] \mathrm{G}$ and $\mathrm{C}\left[5-\mathrm{N}^{6}\right] \mathrm{A}$ than from $\mathrm{C}[5-8] \mathrm{G}, \mathrm{C}[5-2] \mathrm{A}$, and $\mathrm{C}[5-8] \mathrm{A}$. The results from the present study afforded important guidance for the application of mass spectrometry for the structure elucidation of other intrastrand/interstrand crosslink lesions. (J Am Soc Mass Spectrom 2009, 20, 611-617) (c) 2009 Published by Elsevier Inc. on behalf of American Society for Mass Spectrometry

$\mathrm{E}$ ndogenous and exogenous sources can lead to the formation of a variety of DNA damage products including abasic sites, single-nucleobase lesions, crosslink lesions, and strand breaks [1,2]. The formation of these lesions is implicated in the natural processes of aging [3] and many pathological conditions including cancer [4] and neurodegeneration [5]. Among those lesions, intrastrand and interstrand crosslink products can form in DNA upon the attack of reactive oxygen species (ROS) induced from the $\gamma$-radiolysis of water or Fenton reaction [6-13]. Recently, the structures of a number of ROS-induced intrastrand crosslink lesions of DNA have been identified [6-11, 14-20]. Biochemical studies revealed that this type of lesion could be subjected to repair by nucleotide excision repair enzymes [21, 22]. In addition, these intrastrand crosslink lesions could block replicative DNA polymerases and induce errors during replication by translesion synthesis DNA polymerases [12, 13, 17, 23], underscoring the biological significances of this group of DNA lesions.

Mass spectrometry has evolved into a powerful technique for the structure elucidation and quantification of nucleic acid components and their derivatives

Address reprint requests to Dr. Yinsheng Wang, University of California at Riverside, Department of Chemistry (027), 900 University Avenue, Riverside, CA 92521-0403. E-mail: yinsheng.wang@ucr.edu that play important roles in numerous fundamental biological processes [24, 25]. To quantify these intrastrand crosslink lesions formed in vitro or in vivo by liquid chromatography-tandem mass spectrometry (LC-MS/MS) with the isotope-dilution method [12, 13, $19,26]$, we synthesized the stable isotope-labeled analogs of a number of intrastrand crosslink-bearing dinucleoside monophosphates (Scheme 1). Since the stable isotopes ${ }^{15} \mathrm{~N}$ and ${ }^{13} \mathrm{C}$ are selectively incorporated into the pyrimidine nucleoside of the crosslinked dinucleoside monophosphates, this offers us an opportunity to examine the fragmentation chemistry of these crosslinks. The outcome of the study may help us to better understand the cleavage pathways of this type of lesions so that it may provide a basis for the structure elucidation of new intrastrand crosslink lesions by mass spectrometry.

\section{Experimental}

\section{Materials}

$\left[2-{ }^{13} \mathrm{C}, 1,3-{ }^{15} \mathrm{~N}\right]-5-$ Bromo- 2 -deoxyuridine $\quad\left(\left[2-{ }^{13} \mathrm{C}, 1,3-{ }^{15} \mathrm{~N}\right]-5-\right.$ BrdU) was obtained from Cambridge Isotope Laboratories (Andover, MA, USA). All other chemicals were obtained from either Sigma-Aldrich (St. Louis, MO, USA) or VWR International (West Chester, PA, USA). Compound $\left[1,3-{ }^{15} \mathrm{~N}, 2^{\prime}-\mathrm{D}\right]-2^{\prime}$-deoxycytidine was synthe-
(C) 2009 Published by Elsevier Inc. on behalf of American Society for Mass Spectrometry. 1044-0305/09/\$32.00

doi:10.1016/j.jasms.2008.11.020
Published online December 6, 2008 Received December 11, 2006 Revised November 24, 2008 Accepted November 25, 2008 

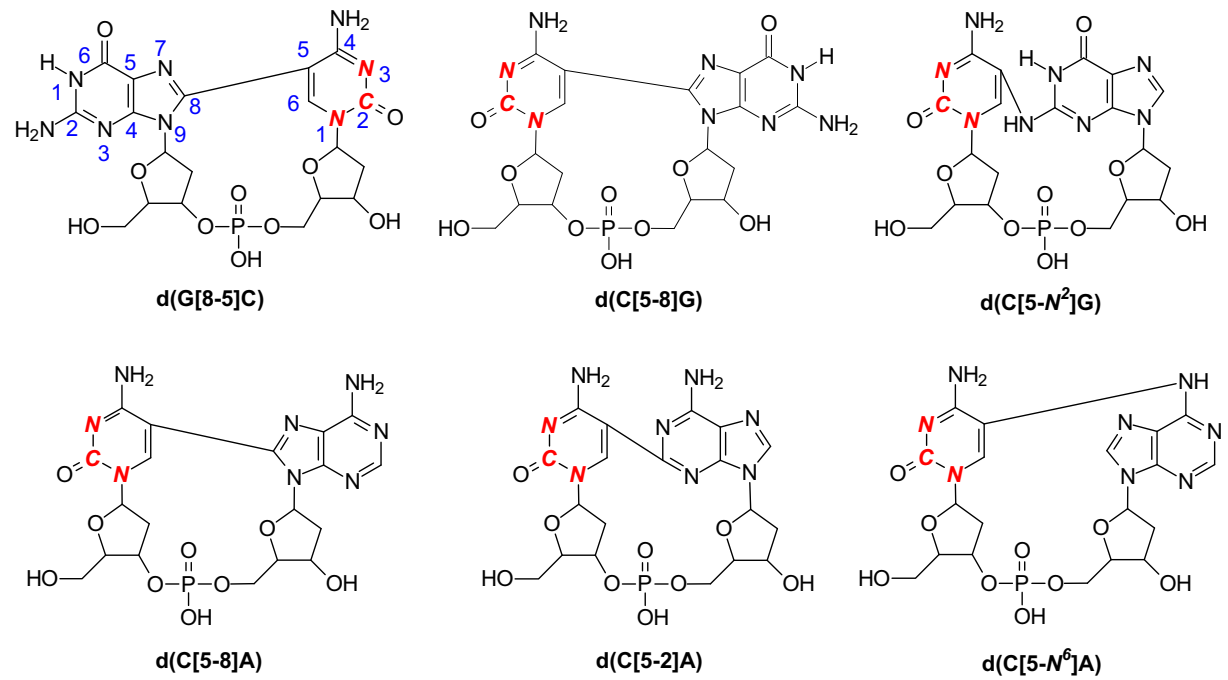

a. isotopic-labeled atoms are labeled as red italic.

Scheme 1

sized following previously described procedures $[8,19]$. The isotopically labeled $\mathrm{d}(\mathrm{G}[8-5] \mathrm{C}), \mathrm{d}(\mathrm{C}[5-8] \mathrm{G}), \mathrm{d}(\mathrm{C}[5-$ $\left.\left.N^{2}\right] \mathrm{G}\right), \mathrm{d}\left(\mathrm{C}\left[5-N^{6}\right] \mathrm{A}\right), \mathrm{d}(\mathrm{C}[5-2] \mathrm{A}), \quad$ and $\mathrm{d}(\mathrm{C}[5-8] \mathrm{A})$ (Scheme 1) were synthesized starting from $\left[2-{ }^{13} \mathrm{C}, 1,3-\right.$ $\left.{ }^{15} \mathrm{~N}\right]-5$-bromo-2'-deoxycytidine-containing dinucleoside monophosphates and oligodeoxynucleotides according to the published procedures for the preparation of the relevant unlabeled compounds $[9,10,20]$. In this respect, the $\left[2-{ }^{13} \mathrm{C}, 1,3-{ }^{15} \mathrm{~N}\right]-5-\mathrm{BrdC}$-bearing substrates were synthesized from $\left[2-{ }^{13} \mathrm{C}, 1,3-{ }^{15} \mathrm{~N}\right]-5-\mathrm{BrdU}$ by using phosphoramidite chemistry [27]. The purities and identities of the synthesized isotope-labeled compounds were verified by HPLC and mass spectrometry.

\section{Electrospray Ionization-Mass Spectrometry (ESI-MS)}

ESI-MS experiments were carried out on an LCQ Deca $\mathrm{XP}$ ion-trap mass spectrometer (ThermoFinnigan, San Jose, CA, USA). For ESI-MS measurements, the crosslink-bearing dinucleoside monophosphates were prepared in a $2-\mu \mathrm{M}$ aqueous solution containing $50 \%$ methanol and $0.2 \%$ formic acid, which was also added to the sample solutions for experiments in the positiveion mode. The solution was infused directly into the mass spectrometer with a syringe pump at a flow rate of $2.0 \mu \mathrm{L} / \mathrm{min}$. The spray voltages were 4.5 and $3.0 \mathrm{kV}$ for experiments in the positive- and negative-ion modes, respectively, and the temperature for the heated capillary was maintained at $225^{\circ} \mathrm{C}$. The automated gain control (AGC) feature was used and the maximum numbers of ions were set at $5 \times 10^{7}$ and $4 \times 10^{7}$ in MS and $\mathrm{MS}^{n}$ modes, respectively. The normalized collisional energy was optimized (15-35\%) so that the precursor ion was clearly present $(10-40 \%)$, but not the most abundant in the product-ion spectrum. Isolation width was set at 3 and $2 \mathrm{~m} / z$ units for MS/MS and $\mathrm{MS}^{n}$, respectively. To obtain product-ion spectra for lowmass precursor ions, the activation $Q$ was increased slightly (in a range of $0.25-0.29$ ) to minimize the loss of fragment ions of low $m / z$ values.

\section{Results and Discussion}

The product-ion spectra of many intrastrand crosslinkbearing dinucleoside monophosphates discussed herein have been reported previously [8-10, 14, 20]. However, some dissociation pathways remain elusive, attributed largely to the fact that the origins of neutral losses cannot be revealed without the isotope-labeled samples. We took advantage of the availability of dinucleoside monophosphates carrying a stable isotope-incorporated pyrimidine nucleoside (Scheme 1) and the multistage MS $\left(\mathrm{MS}^{n}\right)$ capability of an ion-trap mass spectrometer to elucidate the fragmentation pathways of the crosslink lesions. These data, together with the previously reported $\mathrm{MS}^{2}$ and $\mathrm{MS}^{n}$ results of the corresponding unlabeled compounds [8-10, 14, 20], allowed for the unambiguous assignments of the origins of major neutral-loss fragments and the revelation of new fragmentation pathways.

All crosslink lesions studied here harbor a covalent bond between the $\mathrm{C} 5$ of cytosine and a ring carbon or exocyclic nitrogen atom of its neighboring purine base. The protonated and deprotonated ions of the covalently linked nucleobase portion can often be produced from the fragmentation of the crosslink-bearing dinucleoside monophosphates. Thus, we reason that elucidation of the dissociation pathways of those covalently joined nucleobases may build up a basis for using $\mathrm{MS}^{n}$ for the structure determination of other crosslink lesions of DNA. In this context, it is worth noting that any pair of sequence isomers-such as $\mathrm{d}(\mathrm{C}[5-8] \mathrm{A}) / \mathrm{d}(\mathrm{A}[8-5] \mathrm{C})$ and $d(C[5-8] G) / d(G[8-5] C)$ - are cleaved to the iden- 
tical protonated or deprotonated ions of the crosslinked nucleobase portion because the sequence difference is revoked once the backbone 2-deoxyribose/phosphate is eliminated. In light of this, we refer, in the following discussion, to the crosslinked nucleobase portion of $\mathrm{d}(\mathrm{C}[5-8] \mathrm{G})$ and $\mathrm{d}(\mathrm{G}[8-5] \mathrm{C})$ as $\mathrm{C}[5-8] \mathrm{G}$, and similar annotations are used for the nucleobase portions of other intrastrand crosslinks.

\section{$C[5-8] G$ and $C\left[5-N^{2}\right] G$}

It was recently reported that, similar to adenine [28], the protonated ions of cytosine and some of its oxidatively modified derivatives could undergo Dimroth-like rearrangement in the gas phase $[29,30]$. This rearrangement allows for the switching of the exocyclic $\mathrm{NH}_{2}$ nitrogen with the N3 nitrogen of cytosine. We began by asking whether the same cleavage chemistry occurs for the two isomeric crosslinks formed between cytosine and its neighboring guanine, i.e., $\mathrm{C}[5-8] \mathrm{G}$ and $\mathrm{C}\left[5-\mathrm{N}^{2}\right] \mathrm{G}$. From the perspective that $\mathrm{HNCO}$ is commonly lost from the cytosine component, we would expect to observe the loss of $\mathrm{HN}^{13} \mathrm{CO}$, in addition to $\mathrm{H}^{15} \mathrm{~N}^{13} \mathrm{CO}$, if the same rearrangement occurs for $\mathrm{C}[5-8] \mathrm{G}$ or $\mathrm{C}\left[5-N^{2}\right] \mathrm{G}$. It turned out that the ions arising from the expulsion of both $\mathrm{H}^{15} \mathrm{~N}^{13} \mathrm{CO}$ and $\mathrm{HN}^{13} \mathrm{CO}$ (of $m / z 219$ and 220) are of high abundance in the product-ion spectrum $\left(\mathrm{MS}^{3}\right)$ of the $[\mathrm{M}+\mathrm{H}]^{+}$ion of $\mathrm{C}[5-8] \mathrm{G}$ (Figure $1 \mathrm{~b}$ ), supporting the occurrence of a Dimroth-like rearrangement.

Other than the elimination of labeled $\mathrm{HNCO}$, we also observed the losses of both $\mathrm{NH}_{3}$ and ${ }^{15} \mathrm{NH}_{3}$, with the latter being less facile [29]. In this context, our previous study on the fragmentation of the protonated ion of unmodified cytosine revealed that ammonia can be eliminated mainly from the N3 nitrogen atom and a small fraction of ammonia can also be lost from the exocyclic N4 nitrogen [29]. We speculate that two factors may account for the preferential loss of unlabeled $\mathrm{NH}_{3}$ over ${ }^{15} \mathrm{NH}_{3}$ from the protonated $\mathrm{C}[5-8] \mathrm{G}$. First, the unlabeled $\mathrm{NH}_{3}$ can also be eliminated from the guanine portion of the crosslink. Along this line, previous work by Gregson et al. [31] showed that the protonation at the N1 of guanine and the subsequent cleavage of the N1-C2 bond can result in the loss of an ammonia from the N1 and N2 of guanine. Second, attachment of the $\mathrm{C} 5$ of cytosine with the $\mathrm{C} 8$ of guanine may also alter the fragmentation of the cytosine portion by leading to the facile loss of ammonia from the exocyclic N4 nitrogen atom of cytosine.

In sharp contrast, the loss of $\mathrm{H}^{15} \mathrm{~N}^{13} \mathrm{CO}$, but not $\mathrm{HN}^{13} \mathrm{CO}$, was evident in the corresponding product-ion spectrum resulting from the fragmentation of the [M $\mathrm{H}]^{-}$ion of $\mathrm{C}[5-8] \mathrm{G}$ (Figure 1d), underscoring the prohibition of the Dimroth-like rearrangement for the $[\mathrm{M}-\mathrm{H}]^{-}$ion of the conjugate, where the $\mathrm{C} 5$ of cytosine is covalently bonded with the $\mathrm{C} 8$ of guanine. Moreover, we found the loss of an unlabeled $\mathrm{NH}_{3}$ to give the ion of $m / z 245$ in low abundance (Figure 1d).

We next examined the fragmentation of $C\left[5-N^{2}\right] G$, a crosslink lesion in which the $\mathrm{C} 5$ of cytosine is coupled to the exocyclic $\mathrm{NH}_{2}$ group of its neighboring guanine. It turned out that, upon the collisional activation of the

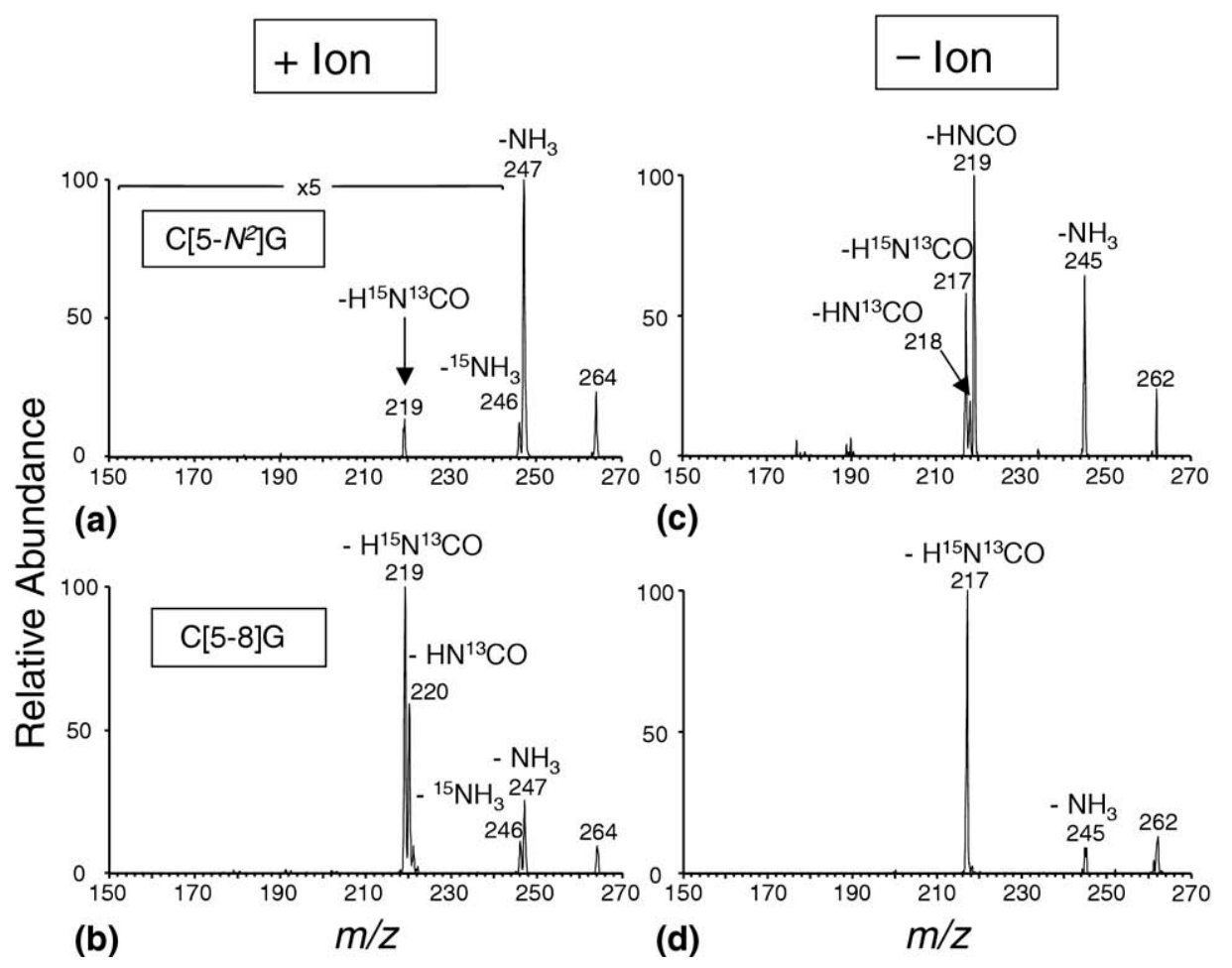

Figure 1. The product-ion spectra of the $[\mathrm{M}+\mathrm{H}]^{+}(\mathbf{a}$ and $\mathbf{b})$ and $[\mathrm{M}-\mathrm{H}]^{-}$ions (c and $\left.\mathbf{d}\right)$ of the crosslinked nucleobase components of the isotope-labeled $C\left[5-N^{2}\right] G(\mathbf{a}, \mathbf{c})$ and $C[5-8] G(\mathbf{b}, \mathbf{d})$. 
protonated ion, the fragment ion arising from the loss of unlabeled $\mathrm{NH}_{3}$ dominates the product-ion spectrum. Additionally, whereas the ion formed from the loss of $\mathrm{H}^{15} \mathrm{~N}^{13} \mathrm{CO}$ was of very low abundance, the ion emanating from the elimination of an $\mathrm{HN}^{13} \mathrm{CO}$ was not detectable (Figure 1a). These results showed that the Dimrothlike rearrangement does not occur for the $[\mathrm{M}+\mathrm{H}]^{+}$ion of $C\left[5-N^{2}\right] G$. In this context, it is worth noting that the ion resulting from the loss of $\mathrm{H}^{15} \mathrm{~N}^{13} \mathrm{CO}$ is of low abundance; nonetheless, the results were reproducible. By contrast, the losses of $\mathrm{HNCO}, \mathrm{H}^{15} \mathrm{~N}^{13} \mathrm{CO}$, and $\mathrm{HN}^{13} \mathrm{CO}$, in decreasing preference, were among the most abundant neutral losses found in negative-ion $\mathrm{MS}^{3}$ (Figure 1c). The unlabeled $\mathrm{HNCO}$ can only be eliminated from guanine. The $\mathrm{HNCO}$ loss resulting from the Dimroth-like rearrangement of the cytosine component is estimated to be about $30 \%$ by comparing the relative abundances of the ions of $\mathrm{m} / \mathrm{z} 218$ and $\mathrm{m} / \mathrm{z}$ 217 (Figure 1c).
$C[5-8] A, C[5-2] A$, and $C\left[5-N^{6}\right] A$

Intrastrand crosslink products formed between cytosine and its neighboring adenine are of special interest because we identified three isomers, in which the $\mathrm{C} 5$ of cytosine is coupled to the N6, C2, or C8 of adenine to yield $\mathrm{C}\left[5-\mathrm{N}^{6}\right] \mathrm{A}, \mathrm{C}[5-2] \mathrm{A}$, and $\mathrm{C}[5-8] \mathrm{A}$, respectively (Scheme 1) [10]. In the product-ion spectra of the [M+ $\mathrm{H}]^{+}$ions of the nucleobase portions of the three crosslinks, we found that the neutral loss of $\mathrm{NH}_{3}(\mathrm{~m} / \mathrm{z}$ 231) occurs much more readily for $C\left[5-N^{6}\right] A$ than for $\mathrm{C}$ [5-8]A and C[5-2]A (Figure 2a-c). The fragment ion arising from the loss of ${ }^{15} \mathrm{NH}_{3}$ (i.e., the ion of $m / z$ 230) was also found for $\mathrm{C}\left[5-N^{6}\right] \mathrm{A}$, although at an abundance of about $1 / 3$ of that for the ion emanating from the loss of unlabeled $\mathrm{NH}_{3}$ (the $m / z 231$ ion). As discussed earlier, protonated cytosine can undergo the neutral loss of ammonia from both the N3 and N4 nitrogen atoms, with the former loss being more facile [29]. In addition,

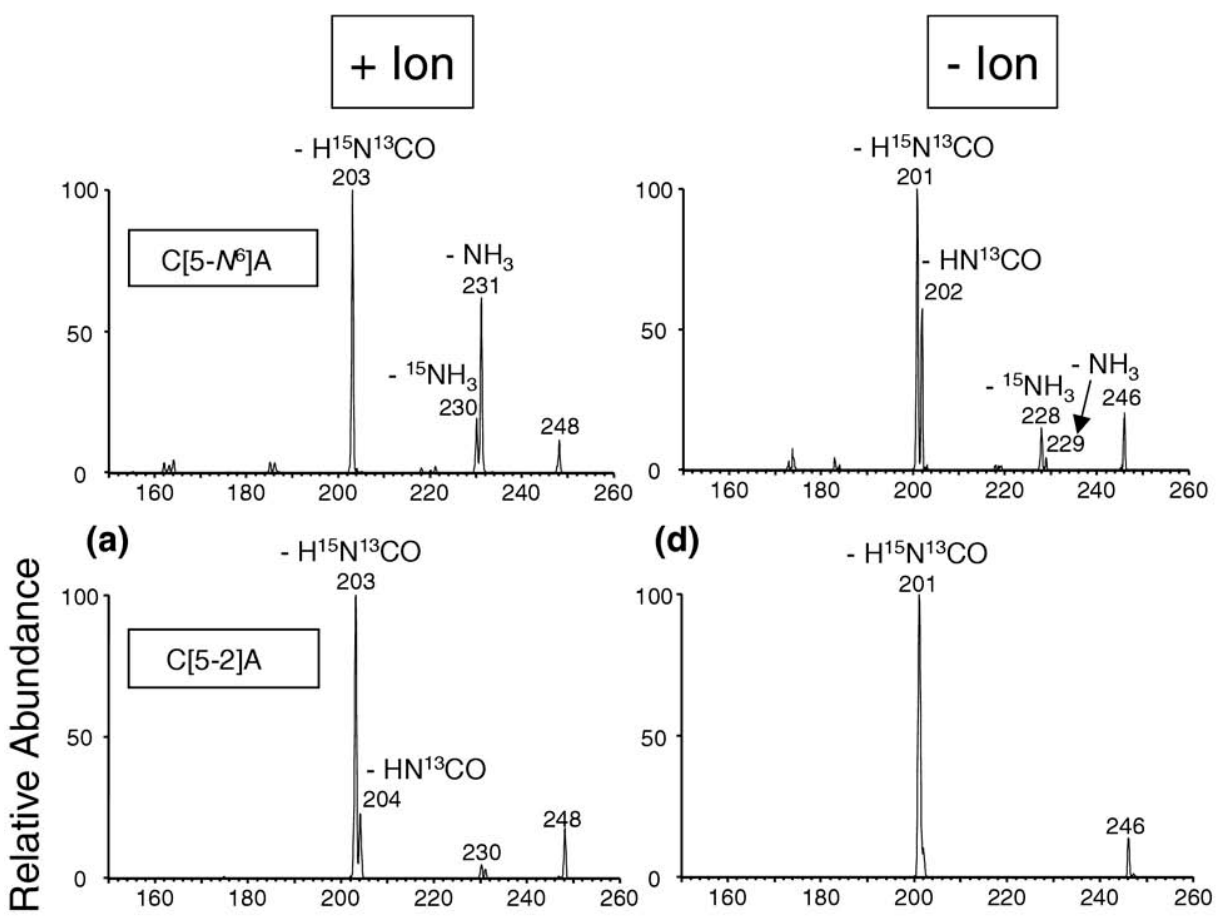

(b)

(e)
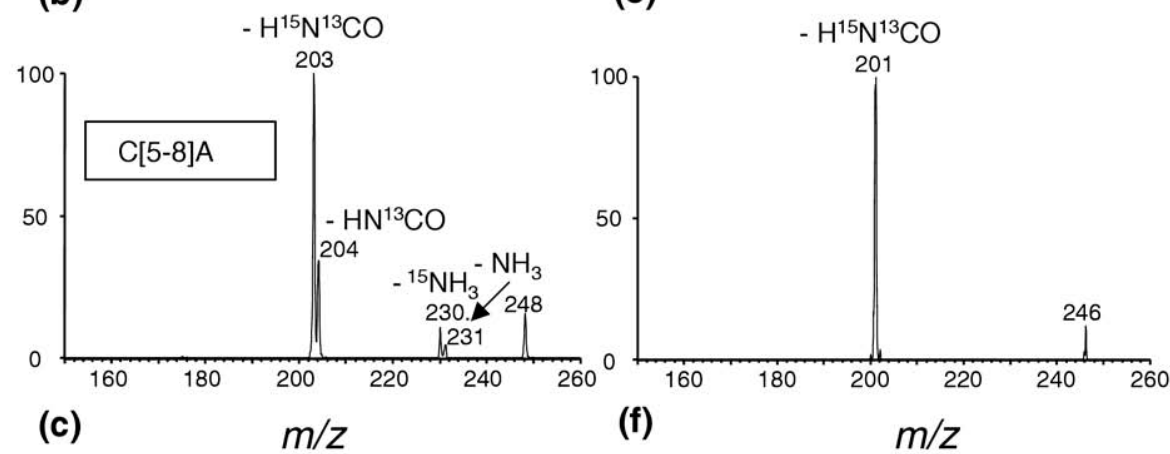

(c)

$m / z$

Figure 2. The product-ion spectra of the $[\mathrm{M}+\mathrm{H}]^{+}(\mathbf{a}, \mathbf{b}$, and $\mathbf{c})$ and $[\mathrm{M}-\mathrm{H}]^{-}$ions $(\mathbf{b}, \mathbf{e}$, and $\mathbf{f})$ of the crosslinked nucleobase portions of the stable isotope-labeled C[5- $\left.N^{6}\right] A(\mathbf{a}, \mathbf{d}), C[5-2] \mathrm{A}(\mathbf{b}, \mathbf{e})$, and C[5-8]A (c, f) (see Scheme $\mathbf{1}$ for the isotope labels). 
ammonia can be eliminated from the N1 or N6 nitrogen of protonated adenine, with the loss from the former nitrogen being slightly preferred [32]. Thus, similar to the preferential loss of unlabeled $\mathrm{NH}_{3}$ over ${ }^{15} \mathrm{NH}_{3}$ from $\mathrm{C}\left[5-N^{2}\right] \mathrm{G}$, the more favorable loss of unlabeled $\mathrm{NH}_{3}$ from $\mathrm{C}\left[5-\mathrm{N}^{6}\right] \mathrm{A}$ might be attributed to the elimination of $\mathrm{NH}_{3}$ from the adenine component of the crosslink or attributed to the more facile loss of $\mathrm{NH}_{3}$ from the $\mathrm{N} 4$ of cytosine emanating from the covalent linkage of the $\mathrm{C} 5$ of cytosine with the adenine.

Similar to what we found for the isomeric crosslinks involving cytosine and guanine, the three crosslinks formed between cytosine and adenine also exhibit a difference in their susceptibility toward a Dimroth-like rearrangement. The ion of $\mathrm{m} / \mathrm{z} 204$, arising from the neutral loss of an $\mathrm{HN}^{13} \mathrm{CO}$ after the rearrangement, has relative abundances of roughly 35 and $20 \%$ for C[5-8]A and C[5-2]A, respectively, although this ion is almost absent for $\mathrm{C}\left[5-\mathrm{N}^{6}\right] \mathrm{A}$ (Figure 2). The above-cited results, therefore, demonstrate that the Dimroth-like rearrangement is prohibited for the $[\mathrm{M}+\mathrm{H}]^{+}$ion of $\mathrm{C}\left[5-N^{6}\right] \mathrm{A}$, but is allowed for the $[\mathrm{M}+\mathrm{H}]^{+}$ions of $\mathrm{C}[5-8] \mathrm{A}$ and $\mathrm{C}[5-2] \mathrm{A}$. This finding is in keeping with the inhibition of the Dimroth-like rearrangement for the $[\mathrm{M}+\mathrm{H}]^{+}$ion of $C\left[5-N^{2}\right] G$, but not C [5-8]G (see previous text). Therefore, we may conclude that the covalent linkage of the C5 of cytosine with the exocyclic amino nitrogen of a purine base-i.e., the N6 of adenine or the N2 of guanine-results in the inhibition of the Dimroth-like rearrangement for the protonated ion of the crosslinked nucleobase portion. The underlying cause for this inhibition remains unclear.

The product-ion spectra acquired in the negative-ion mode revealed that all three cytosine-adenine crosslinks undergo a very facile loss of the labeled HNCO moiety, although the fragment ion arising from the loss of ${ }^{15} \mathrm{NH}_{3}$ was also found in the product-ion spectrum of $\mathrm{C}\left[5-N^{6}\right] \mathrm{A}$. In addition, the negative-ion spectra for the three isomers exhibited a completely opposite trend in Dimroth-like rearrangement for the three isomers, i.e., the rearrangement was found for $\mathrm{C}\left[5-N^{6}\right] \mathrm{A}$, but not for the other two isomers. In this context, the product-ion spectrum of $\mathrm{C}\left[5-\mathrm{N}^{6}\right]$ A showed two major fragment ions of $m / z 201$ and 202 (Figure 2d), which are attributed to the losses of $\mathrm{H}^{15} \mathrm{~N}^{13} \mathrm{CO}$ and $\mathrm{HN}^{13} \mathrm{CO}$, respectively. The latter neutral loss can form only from the Dimroth-like rearrangement product of $\mathrm{C}\left[5-\mathrm{N}^{6}\right] \mathrm{A}$. On the contrary, the ion resulting from the loss of $\mathrm{H}^{15} \mathrm{~N}^{13} \mathrm{CO}(\mathrm{m} / \mathrm{z} 201)$ dominates the product-ion spectra of C[5-8]A and C[5-2]A (Figure 2e and $f$ ), whereas the elimination of $\mathrm{HN}^{13} \mathrm{CO}$ is barely detectable, supporting that the Dimroth-like rearrangement does not occur for the $[\mathrm{M}-\mathrm{H}]^{-}$ions of these two isomers. This result is consistent with what we observed for the two isomeric cytosine-guanine crosslinks, where the Dimroth rearrangement was found for the $[\mathrm{M}-\mathrm{H}]^{-}$ion of $\mathrm{C}\left[5-\mathrm{N}^{2}\right] \mathrm{G}$, but not C[5-8]G.

The unique structural features of the crosslinks may account for the difference in their susceptibilities to- ward a Dimroth-like rearrangement in the negative-ion mode. For deprotonated ions, the Dimroth-like rearrangement of the cytosine portion necessitates the cleavage of the $\mathrm{C} 2-\mathrm{N} 3$ bond of cytosine. Therefore, the deprotonation of the $\mathrm{N} 1$ of cytosine and the localization of the negative charge on the carbonyl oxygen $(\mathrm{O} 2)$ of cytosine are expected to promote the cleavage (Scheme 2). In $C\left[5-N^{6}\right] A$ and $C\left[5-N^{2}\right] G$, the two nucleobases remain as two isolated $\pi$ systems, which may favor the localization of the negative charge on the $\mathrm{O} 2$ of cytosine. In the other three lesions-i.e., C[5-8]G, C[5-8]A, and $\mathrm{C}[5-2] \mathrm{A}-$ the conjugation of the $\pi$ systems of the two nucleobases renders the negative charge delocalized between the two nucleobases. The decreased negative charge density on the $\mathrm{O} 2$ of cytosine may disfavor the cleavage of the $\mathrm{C} 2-\mathrm{N} 3$ bond of cytosine, thereby inhibiting the subsequent Dimroth-like rearrangement.

We also examined the fragmentation of the [M $\mathrm{H}]^{-}$ion of $\left[1,3-{ }^{15} \mathrm{~N}\right]$ cytosine and it turned out that close to $50 \%$ of the HNCO loss can arise from the Dimrothlike rearrangement product of the deprotonated cytosine (Figure 3). In this context, the Dimroth-like rearrangement occurred at somewhat lower frequency $(\sim 30 \%)$ for the protonated cytosine [29]. It is also worth noting that we did not find a fragment ion emanating from the loss of ammonia in Figure 3, whereas this loss occurs readily during the collisional activation of the protonated cytosine [29]. This difference might be attributed to the fact that there are only two acidic protons in deprotonated cytosine and the loss of ammonia would require the transfer of a nonexchangeable proton to the nitrogen atom to be eliminated. However, no such transfer is needed for the loss of ammonia from protonated cytosine.

\section{Conclusions}

Several general conclusions can be drawn from the results presented here. First, upon collisional activation of the protonated or deprotonated ions of the crosslinked nucleobases, the pyrimidine base is more susceptible to cleavage than is the purine base, possibly as a result of the lower level of conjugation for the pyrimidine bases than

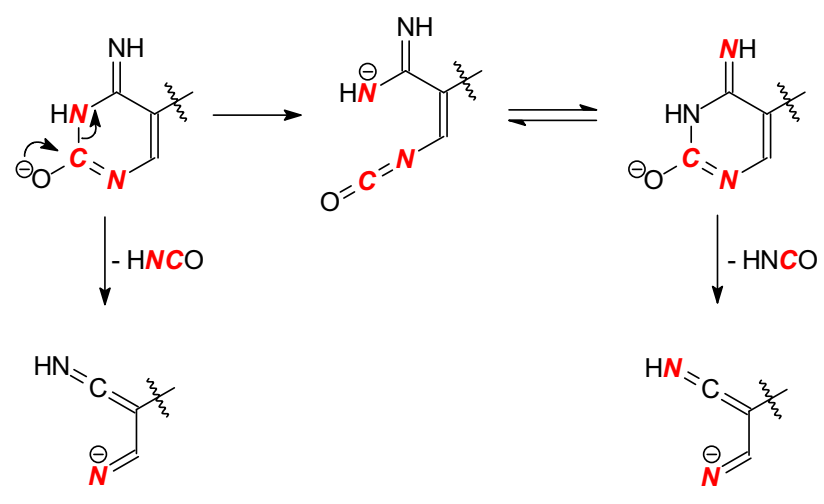

Scheme 2 


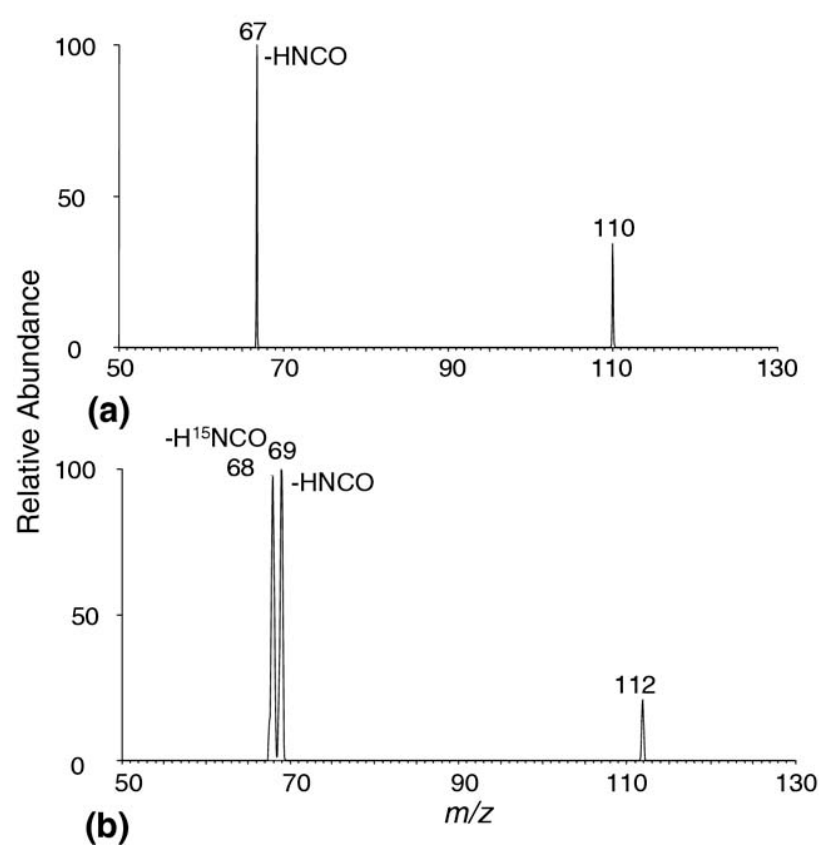

Figure 3. Product-ion spectra of the $[\mathrm{M}-\mathrm{H}]^{-}$ions of cytosine (a) and $\left[1,3-{ }^{15} \mathrm{~N}\right]$ cytosine $(\mathbf{b})$. The precursors ions were generated from the collisional activation of the $[\mathrm{M}-\mathrm{H}]^{-}$ions of the corresponding nucleosides.

for the purine bases. Second, we found that, in the positive-ion mode, the Dimroth-like rearrangement can occur for the crosslinks where cytosine is conjugated with its neighboring adenine or guanine base to yield an extended $\pi$ system: i.e., C[5-8]G, C[5-8]A, and $\mathrm{C}[5-2] \mathrm{A}$. This rearrangement, however, is not found for $\mathrm{C}\left[5-N^{6}\right] \mathrm{A}$ or $\mathrm{C}\left[5-\mathrm{N}^{2}\right] \mathrm{G}$, where the $\mathrm{C} 5$ of cytosine is coupled to an exocyclic amino nitrogen of the neighboring purine base. By contrast, such a rearrangement occurs upon the fragmentation of the deprotonated ions of $\mathrm{C}\left[5-N^{6}\right] \mathrm{A}$ and $\mathrm{d}\left[5-\mathrm{N}^{2}\right] \mathrm{G}$, but not for C[5-8]G, C[58]A, or C[5-2]A. Furthermore, when the C5 of cytosine is conjugated with the exocyclic amino group of a purine base-i.e., the N2 of guanine or the N6 of adenine-the loss of ammonia from the crosslinked nucleobase portion is much more facile than the same loss from the crosslinks in which the $\mathrm{C} 5$ of cytosine is linked with the ring carbon of its neighboring purine base, i.e., the $\mathrm{C} 2$ or $\mathrm{C} 8$ of adenine and the $\mathrm{C} 8$ of guanine.

The fragmentation chemistry reported here may be useful for the structure elucidation of other intrastrand crosslink lesions. In addition, it may be applied for gaining insights into the structures of interstrand crosslink lesions if the crosslinked nucleobase component can be produced upon the fragmentation of the interstrand crosslink-bearing nucleosides/nucleotides.

\section{Acknowledgments}

The authors thank Haizheng Hong and Yu Zeng for providing crosslink products for this study. This work was supported by National Cancer Institute Grant R01 CA101864.

\section{References}

1. Cooke, M. S.; Evans, M. D.; Dizdaroglu, M.; Lunec, J. Oxidative DNA Damage: Mechanisms, Mutation, and Disease. FASEB J. 2003, 17, 1195-1214.

2. Evans, M. D.; Dizdaroglu, M.; Cooke, M. S. Oxidative DNA Damage and Disease: Induction, Repair and Significance. Mutat. Res. 2004, 567, $1-61$.

3. Finkel, T.; Holbrook, N. J. Oxidants, Oxidative Stress and the Biology of Ageing. Nature 2000, 408, 239-247.

4. Hussain, S. P.; Hofseth, L. J.; Harris, C. C. Radical Causes of Cancer. Nat. Rev. Cancer 2003, 3, 276-285.

5. Lu, T.; Pan, Y.; Kao, S. Y.; Li, C.; Kohane, I.; Chan, J.; Yankner, B. A. Gene Regulation and DNA Damage in the Ageing Human Brain. Nature 2004, $429,883-891$.

6. Box, H. C.; Budzinski, E. E.; Dawidzik, J. B.; Gobey, J. S.; Freund, H. G. Free Radical-Induced Tandem Base Damage in DNA Oligomers. Free Radic. Biol. Med. 1997, 23, 1021-1030.

7. Box, H. C.; Budzinski, E. E.; Dawidzik, J. B.; Wallace, J. C.; Iijima, H. Tandem Lesions and Other Products in X-irradiated DNA Oligomers. Radiat. Res. 1998, 149, 433-439.

8. Zhang, Q. B.; Wang, Y.-S. Independent Generation of 5-(2'Deoxycytidinyl)methyl Radical and the Formation of a Novel Cross-link Lesion between 5-Methylcytosine and Guanine. J. Am. Chem. Soc. 2003 125, 12795-12802.

9. Zeng, Y.; Wang, Y.-S. Facile Formation of an Intrastrand Cross-link Lesion between Cytosine and Guanine upon Pyrex-filtered UV Light Irradiation of $\mathrm{d}\left({ }^{\mathrm{Br}} \mathrm{CG}\right)$ and Duplex DNA Containing 5-Bromocytosine. J. Am. Chem. Soc. 2004, 126, 6552-6553.

10. Hong, H. Z.; Wang, Y.-S. Formation of Intrastrand Cross-link Products between Cytosine and Adenine from UV Irradiation of $\mathrm{d}\left({ }^{\mathrm{Br}} \mathrm{CA}\right)$ and Duplex DNA Containing a 5-Bromocytosine. J. Am. Chem. Soc. 2005, 127 13969-13977.

11. Liu, Z. J.; Gao, Y.; Zeng, Y.; Fang, F.; Chi, D.; Wang, Y.-S. Isolation and Characterization of a Novel Cross-link Lesion in $\mathrm{d}(\mathrm{CpC})$ Induced by One-Electron Photooxidation. Photochem. Photobiol. 2004, 80, 209-215.

12. Jiang, Y.; Hong, H.; Cao, H.; Wang, Y. In Vivo Formation and In Vitro Replication of a Guanine-Thymine Intrastrand Cross-link Lesion. Biochemistry 2007, 46, 12757-12763.

13. Hong, H.; Cao, H.; Wang, Y. Formation and Genotoxicity of a Guanine Cytosine Intrastrand Cross-link Lesion In Vivo. Nucleic Acids Res. 2007, $35,7118-7127$.

14. Bellon, S.; Ravanat, J. L.; Gasparutto, D.; Cadet, J. Cross-linked Thymine-Purine Base Tandem Lesions: Synthesis, Characterization, and Measurement in Gamma-irradiated Isolated DNA. Chem. Res. Toxicol. 2002, 15, 598-606.

15. Liu, Z.; Gao, Y.; Wang, Y. Identification and Characterization of a Novel Cross-link Lesion in $\mathrm{d}(\mathrm{CpC})$ upon 365-nm Irradiation in the Presence of 2-Methyl-1,4-naphthoquinone. Nucleic Acids Res. 2003, 31, 5413-5424.

16. Zhang, Q.; Wang, Y. Independent Generation of the 5-Hydroxy-5,6dihydrothymidin-6-yl Radical and Its Reactivity in Dinucleoside Monophosphates. J. Am. Chem. Soc. 2004, 126, 13287-13297.

17. Gu, C.; Wang, Y. LC-MS/MS Identification and Yeast Polymerase eta Bypass of a Novel Gamma-irradiation-induced Intrastrand Cross-link Lesion G[8-5]C. Biochemistry 2004, 43, 6745-6750.

18. Zhang, Q.; Wang, Y. Generation of 5-(2'-Deoxycytidyl)methyl Radical and the Formation of Intrastrand Cross-link Lesions in Oligodeoxyribonucleotides. Nucleic Acids Res. 2005, 33, 1593-1603.

19. Hong, H. Z.; Cao, H. C.; Wang, Y.-S.; Wang, Y.-S. Identification and Quantification of a Guanine-Thymine Intrastrand Crosslink Lesion Induced by $\mathrm{Cu}(\mathrm{II}) / \mathrm{H}_{2} \mathrm{O}_{2} /$ Ascorbate. Chem. Res. Toxicol. 2006, 19, $614-$ 621.

20. Zeng, Y.; Wang, Y. Sequence-dependent Formation of Intrastrand Crosslink Products from the UVB Irradiation of Duplex DNA Containing a 5-Bromo-2'-deoxyuridine or 5-Bromo-2'-deoxycytidine. Nucleic Acids Res. 2006, 34, 6521-6529.

21. Yang, Z.; Colis, L. C.; Basu, A. K.; Zou, Y. Recognition and Incision of Gamma-radiation-induced Cross-linked Guanine-Thymine Tandem Lesion G[8,5-Me]T by UvrABC Nuclease. Chem. Res. Toxicol. 2005, 18, $1339-1346$.

22. Gu, C.; Zhang, Q.; Yang, Z.; Wang, Y.; Zou, Y.; Wang, Y. Recognition and Incision of Oxidative Intrastrand Cross-link Lesions by UvrABC Nuclease. Biochemistry 2006, 45, 10739-10746.

23. Gu, C.; Wang, Y. Thermodynamic and In-Vitro Replication Studies of an Intrastrand Crosslink Lesion G[8-5]C. Biochemistry 2005, 44, 8883-8889.

24. Banoub, J. H.; Newton, R. P.; Esmans, E.; Ewing, D. F.; Mackenzie, G. Recent Developments in Mass Spectrometry for the Characterization of Nucleosides, Nucleotides, Oligonucleotides, and Nucleic Acids. Chem. Rev. 2005, 105, 1869-1915.

25. Singh, R.; Farmer, P. B. Liquid Chromatography- Electrospray Ionization-Mass Spectrometry: The Future of DNA Adduct Detection. Carcinogenesis 2006, 27, 178-196.

26. Cao, H.; Wang, Y. Quantification of Oxidative Single-base and Intrastrand Cross-link Lesions in Unmethylated and CpG-methylated DNA Induced by Fenton-type Reagents. Nucleic Acids Res. 2007, 35, 48334844 . 
27. Gait, M. J. Oligonucleotide Synthesis: A Practical Approach; IRL Press Limited, Oxford, UK, 1984.

28. Fujii, T.; Itaya, T. The Dimroth Rearrangement in the Adenine Series: A Review Updated. Heterocycles 1998, 48, 359-390,

29. Cao, H. C.; Wang, Y.-S. Collisionally Activated Dissociation of Protonated 2'-Deoxycytidine, 2'-Deoxyuridine, and Their Oxidatively Damaged Derivatives. J. Am. Soc. Mass Spectrom. 2006, 17, 1335-1341.
30. Jensen, S. S.; Ariza, X.; Nielsen, P.; Vilarrasa, J.; Kirpekar, F. Collisioninduced Dissociation of Cytidine and Its Derivatives. J. Mass Spectrom. 2007, 42, 49-57.

31. Gregson, J. M.; McCloskey, J. A. Collision-induced Dissociation of Protonated Guanine. Int. J. Mass Spectrom. 1997, 165, 475-485.

32. Nelson, C. C.; McCloskey, J. A. Collision-induced Dissociation of Adenine. J. Am. Chem. Soc. 1992, 114, 3661-3668. 